\title{
Review Paper: MDMA and the Brain: A Short Review on the Role of Neurotransmitters in Neurotoxicity
}

\author{
Nor Suliana Mustafa ${ }^{1,2}\left(\mathbb{D}\right.$, Nor Hidayah Abu Bakar ${ }^{1,2} \mathbb{\infty}$, Nasir Mohamad ${ }^{1,2^{*}} \oplus$, Liyana Hazwani Mohd Adnan ${ }^{1,2} \oplus$, Nurul Farah Aina Md \\ Fauzi $^{1,2}$, Abdulsoma Thoarlim ${ }^{1,3}$, Syed Hadzrullathfi Syed Omar ${ }^{1,4}$, Mohd Shafiee Hamzah ${ }^{2,3}$, Zawawi Yusoff ${ }^{2,3}$, Mahdi Jufri ${ }^{5}$, Rashidi Ahmad
}

1. Centre for Research in Addiction (CentRenA), University of Sultan Zainal Abidin, Terengganu, Malaysia.

2. Faculty of Medicine, City Campus, University of Sultan Zainal Abidin, Terengganu, Malaysia.

3. Faculty of Islamic Contemporary Studies, University of Sultan Zainal Abidin, Terengganu, Malaysia.

4. Research Institute for Islamic Products and Malay Civilization University of Sultan Zainal Abidin, Terengganu, Malaysia

5. Faculty of Pharmacy, University of Indonesia, Indonesia.

6. Academic Unit of Emergency Medicine, Faculty of Medicine, University of Malaya, Kuala Lumpur, Malaysia.

citation: Mustafa, N. S., Abu Bakar, N. H., Mohamad, N., Hazwani Mohd Adnan, L., Aina Md Fauzi, N. F., \& Thoarlim, A., et al. (2020). Basic and Clinical Neuroscience, 11(4), 381-388. http://dx.doi.org/10.32598/ben.9.10.485

http://dx.doi.org/10.32598/bcn.9.10.485

Article info:

Received: 24 Jul 2018

First Revision: 10 Aug 2018

Accepted: 19 Feb 2019

Available Online: 01 Jul 2020

Keywords:

MDMA, Neurotransmitter, Brain injuries, Memory,

Therapy

\section{A B S T RA C T}

N-Methyl-3, 4-methylenedioxyamphetamine (MDMA), or ecstasy is a recreational drug of abuse. It is a synthetic substance that affects the body's systems, which its mechanism of action and treatment should be more investigated. MDMA provides an immediate enjoyable feeling by stimulating the release of neurotransmitters, such as dopamine and serotonin in the brain. Unfortunately, abnormal regulation of the brain neurotransmitters, as well as the increased oxidative stress causes damage to the brain neurons after the MDMA exposure. Only a few studies have been done regarding its treatment. Thus, the treatment of MDMA complications should be further explored mainly by targeting its mechanism of action in the neurotransmitter systems. Hence, this study presents a short review regarding the recent findings on the role of neurotransmitters to cause MDMA neurotoxicity. The results will be useful for future research in elucidating the potential treatment based on the targeted mechanisms to treat the neurotoxic effects of MDMA.

\section{* Corresponding Author:}

Nasir Mohamad, ??

Address: Faculty of Medicine, City Campus, University of Sultan Zainal Abidin, Terengganu, Malaysia.

Tel: +60 (17) 9084092

E-mail: drnasirmohamadkb@yahoo.com 


\section{Highlights}

- MDMA is a popular recreational drug with serious effects on animals' behavior and mental health even after long periods of abstinence. Hence, the choices of treatment for MDMA abusers who suffer from the symptoms need to be explored to reduce the effects. Unfortunately, the mechanism of action on how MDMA affects the body and brain needs to be studied first before the best treatment could be applied.

- MDMA administration was reported previously to cause the excessive release of both hippocampal glutamate and 5-HT concentrations mediated by the activations of NMDA receptors and 5-HT receptors, which damage the neurons in the brain.

- MDMA affects the neurotransmitter systems in terms of some changes in the serotonergic, dopaminergic, and GABAergic mechanisms.

- MDMA also affects memory and learning due to the disruption of hippocampal function, mainly through the alterations in dopaminergic and NMDA receptors.

- Several treatments have been proposed for MDMA neurotoxicity, such as the manipulation of the reward pathway, protecting the neurons, and regulating the normal level of 5-HT.

\section{Plain Language Summary}

The amphetamine-type stimulant drugs, such as MDMA or ecstasy become the choice of drug abuse among young people and adults besides opioids, which is due to a feeling of excitement experienced immediately after the administration. The MDMA side effects mostly affect the brain and behavior even after long periods of abstinence. People who want to quit the drug usually fail because of withdrawal complications. Moreover, other complications, such as the lower performance of the learning and memory and also anxiety could disturb their everyday life. Accordingly, this study reviewed the neurotoxic effects of MDMA on neuronal brain activity and MDMA targets, such as receptors and neurotransmitter systems that alter the brain and body functions. Therefore, researchers may target these areas as treatment options. The new findings are always welcomed for the sake of people and the community, especially in addiction.

\section{Introduction}

ubstance abuse remains a worldwide issue. Data reported by the United Nations on Drugs and Crime on the total number of drug addicts worldwide shows the increasing number of drug users every year. Global trends in the estimated number of drug users (15-64 years old) increased from 208 million to 255 million people from 2006 to 2015, while people with drug user disorders increased from 26 million to 29.5 million cases (UNODC, 2017).

Along with the challenges caused by opiates, the increasing number of amphetamine-type stimulants (ATS) users and related disorders are unnoticed, especially for MDMA. MDMA has been declared as an illegal substance in most countries. Some countries, such as Norway, Germany, and Canada have classified it as Schedule I drugs, which is illegal to buy or possess without a license. The National Survey on Drug Use and Health (2004) reported that more than 11 million people have tried MDMA at least once in their lives (NIDA, 2006). Considering a new trend in the substance abuse preference, the MDMA effects will be reviewed focusing on neurotoxicity and neurodegeneration. Besides, the targeted mechanism for the treatment of MDMA complications will be discussed.

Current understanding of the MDMA mechanism of action arises from its effects on the psychological changes and dependence. Psychological changes are explained as the euphoria, sharpened sensory perception, an increase in social performance and empathy, and greater tolerance of the feelings (Kalant, 2001). However, MDMA dependence is still less understood, but it has been reported to be different from other drugs or alcohol (Degenhardt, Bruno, \& Topp 2010). The bio- 
logical mechanisms involved in MDMA exposure are the changes in the serotonergic system, which affects serotonin (5-hydroxytryptamine (5HT)) and dopamine. Interestingly, a study by Popova et al. announced the observations contrary to this theory (Popova, Forsblad, Hashemian, \& Jacobsson, 2016). Thus, there is still limited knowledge about MDMA mechanisms. Therefore, more extensive studies are needed in order to reveal strong evidence about the exact mechanism of MDMA toxicities.

Historical evidence showed that the mechanism of MDMA upon its administration is through its binding affinity to the serotonin receptors (Liechti, Saur, Gamma, Hell, \& Vollenweider, 2000). The activation of these receptors triggers a massive release of neurotransmitters. MDMA also inhibits serotonin reuptake by its binding to the transporter protein, thus prolonging signaling at the synapses. Besides, the MDMA bindings to the plasma membrane transporters are also translocated into the cytoplasm and promote non-exocytotic transmitter release (Verrico, Miller, \& Madras, 2007). This causes the accumulation of the neurotransmitters between the synapses, which can result in excitotoxicity. Although MDMA was reported to improve the emotional and personality problems in psychotherapy as mentioned earlier, its long-term effects can be more adverse. The massive release of serotonin that initially causes the psychotic symptoms can also give rise to the chemical damage to serotonin-releasing cells (Kalant, 2001). Due to the disruption of the normal brain biological system, MDMA can cause damage to the brain structure and nervous system, which increases the loss of neurons and alters the brain functions. Therefore, three main issues, including neuronal damage, alterations in neurotransmitters, and memory impairments will be reviewed in this present article based on the recent studies on the effects of MDMA abuse.

\subsection{Effects of MDMA on neuronal damage}

Neuronal damage is the loss of brain cells either because of the alterations by toxic substances or certain diseases. Neuronal cell death can occur due to the increased production of free radicals by neurotoxins. Memory and learning impairment by MDMA also results from the neuronal damages and dysfunction of the nervous system. MDMA administration was studied to cause neurodegeneration by enhancing the release of free radicals. The free radicals, such as reactive oxygen generation inhibit the activity of mitochondrial complex I (Karuppagounder et al., 2014). The inhibition of mitochondria causes the loss of energy, and con- sequently neuronal death. On the other hand, MDMA affects the hypothalamic-pituitary-adrenal (HPA) axis due to an increase in cortisol levels that is represented by neuropsychological stress in MDMA users (Parrott et al., 1995). Besides, the excessive levels of autophagy are also contributed to the neuronal damage induced by MDMA, which was studied in cultured cortical neurons ( $\mathrm{Li}$ et al., 2014). A recent finding on MDMA neurotoxicity in mice suggested its involvement in the elevation of the neuronal nitric oxide (NO) synthase in the dopaminergic nigrostriatal system that occurred only in mice that received 28 drug administrations (Costa, Morelli, \& Simola, 2018)

Moreover, as mentioned previously, MDMA is a drug with a binding affinity for the specific serotonin receptors. The alteration in the serotonin receptor function (5HT1A) was found in repeated MDMA administrations, especially following administration of high dose MDMA (Bradbury, 2014). A study by Collins et al. (2015) indicated that MDMA can also increase the glutamate release, which was mediated by serotonin receptors. Subsequently, N-methyl-D-aspartic acid (NMDA) receptors are also activated, which then causes the loss of parvalbumin interneurons within the dentate gyrus (DG) of the brain. The loss of parvalbumin neurons in the brain upon MDMA exposure was supported by another study by Anneken et al. (2013), which further explained that the diminished number of the neurons was associated with the activation of serotonin (5-HT) in the hippocampus and the involvements of cyclooxygenase activity that contributes to the increase of glutamate in the DG. It can be generally concluded that the excitation of both hippocampal glutamate and 5-HT concentrations mediated by the activation of NMDA and 5-HT receptors can cause neuronal damage. MDMA was also reported to have considerable effects on 5-HT activity and damage to the 5-HT neuritic tree (Mercer et al., 2017). The deficiency of serotonin transporter also modulated MDMA-mediated neurotoxicity in rats (Lizarraga et al., 2017).

Regarding the long-term effects of MDMA exposure, it was proven that MDMA could reduce the level of serotonin in the cerebrospinal fluid of rats (Mueller et al., 2009; Mustafa et al., 2018). However, some researchers have suggested that MDMA may be able to cause a long-term 5-HT down-regulation without causing structural damage to serotonin neurons (Kish, 2002). MDMA-induced serotonin deficit has been interpreted as neurotoxicity. Unfortunately, there is still an ongoing debate on whether the deficit of serotonin reflects damage to the neurons (Baumann, Wang \& Rothman, 
2007). However, in a clinical study, the brain imaging studies on MDMA users had been drug-free for 20 weeks or longer have not revealed less serotonin transporter binding levels in the brain (Buchert et al., 2003). Brain imaging studies on humans have provided evidence regarding the altered serotonergic functioning in recreational ecstasy users.

Neurotoxic effects of MDMA on dopamine neurons were also reported in rats exposed to MDMA at a low dose, evidenced by the widespread reduction of the number of the neurons upon MDMA exposure (Cadoni et al., 2017; Costa, Morelli \& Simola, 2017). Breivik et al. (2014) also reported that long-term exposure of MDMA affected the serotonergic and dopaminergic transport systems in the rat brain. Tao et al. (2015) suggested that serotonergic transmissions play a role in MDMA-induced syndrome.

In chronic MDMA exposure, serotonergic and GABAergic signaling impairments caused the hippocampal protein deficits in adolescent and young adult rats, and subsequently resulted in the decreased specific structural cytoskeletal neurofilament proteins (GarciaCabrerizo \& Garcia-Fuster, 2015). A recent finding by Mercer et al. (2017) suggested that the damage to GABAergic neurons may be secondary neurotoxicity in repeated and high-dose administration of MDMA, not the primary action of MDMA. A study by Costa et al. (2017) reported that MDMA alters the expression of several proteins involved in GABAergic neurotransmission. Also, MDMA changed the proteins associated with GABAergic neurotransmissions, such as the expression of the different GABA transporters (Simantov \& Peng, 2004).

Hence, MDMA causes neurotoxicity through different mechanisms; either by acting directly on the neuronal brain activity or by other indirect pathways. Future studies regarding the treatment of the detrimental effects caused by MDMA should focus on the compounds that have the healing properties towards the abnormal neurotransmitter regulations and the damaged neurons.

\subsection{Effects of MDMA on memory and learning}

It has been discovered that MDMA impairs learning and memory. A clinical study showed that MDMA users displayed relatively discrete declarative memory impairments, which were quantified by hair analysis for six months, and the pure chronic MDMA use was found to be associated with decreased performance in declarative memory (Wunderli et al., 2017). Another clinical study proved that MDMA users had significantly lower quality of working memory compared with the control groups (Potter, Downey, \& Stough, 2013).

The impairment of memory by MDMA was also studied in vivo. Memory deficit was detected in young mice exposed to MDMA that was explained by the increased expression of early markers of plasticity, observed through the reduction in dopaminergic markers in the substantia nigra. The previous study on rats by Moyano \& Frechilla, (2004) reported that acute MDMA diminished the functions of hippocampal calcium and calmodulin-dependent kinase type II (CaMKII) and reduced the levels of synaptic NMDA receptor subunits, which could explain the impairment of passive avoidance learning. The NMDA receptor, a type of ionotropic glutamate receptors, was reported to be also involved in the rewarding effects of MDMA (GarciaPardo, Escobar-Valero, Rodriguez-Arias, Minarro, \& Aguilar, 2015). MDMA-treated rats also displayed a deficit in recognition memory in the novel recognition test, which was believed to occur due to the damage to dopamine neurons (Cadoni et al., 2017). Hence, the effects of MDMA on memory are seen through the alterations in dopaminergic as well as the disruption of NMDA receptors. Thus, the main focus of the researchers for future studies should be on the treatment through these targeted areas.

\subsection{Previous studies on the therapeutic targets for MDMA toxicity}

The toxicity effects induced by MDMA made the researchers motivated to explore its potential treatments. Several therapeutic methods have been suggested by the researchers for the treatment of MDMA abuse. For example, Garcia-Pardo et al. (2017) recently studied the role of NO pathway in MDMA rewards and they suggested a therapeutic option for MDMA abuse by manipulating this pathway. They also suggested that the NMDA receptor antagonism might be one of the therapeutic targets for MDMA-related problems (Garcia-Pardo et al., 2015). In addition, the potential treatments to protect toxicity caused by MDMA have also been studied. Dextromethorphan and its metabolite, dextrorphan, may have a protective effect against MDMA-induced serotonergic toxicity in the brain (Finnegan, Skratt, Irwin, \& Langston, 1989; Ma et al., 2016). Dextrorphan was believed to prevent the effects of serotonin depletion by MDMA in the striatum, hippocampus, and cortex (Finnegan et al., 1989). 
Furthermore, ketoprofen treatment has reduced the decreased number of parvalbumin-positive GABA interneurons in the DG of the hippocampus upon repeated MDMA administrations. However, the ketoprofen, unfortunately, did not prevent the 5-HT depletion in the hippocampus (Anneken et al., 2013). Another therapeutic option for MDMA abuse is rilmenidine, which is one of the antidepressants (Laurent \& Safar, 1992). It was found recently to protect against MDMA-induced injury via full preservation of 5-HT arbours indicated by imaging (Mercer et al., 2017). Besides, co-administration of acute MDMA and mephedrone showed antidepressant-like activity and improved memory in mice (Budzynska \& Michalak, 2017). Another natural substance was shown to prevent apoptosis induced by MDMA. Ginger was proven to reduce the activation of the caspase cascade responsible for cell death (Asl et al., 2013).

Most of the recent studies and suggestions regarding the targeted treatment for MDMA abuse have focused on attenuating the neurotoxicity and neurotransmitters excitotoxicity in the brain. In future studies, the potential therapeutic substances, either synthetic or natural that can attenuate the long-term effects of MDMA through those involved mechanisms should be highly considered.

\section{Discussion}

In summary, people, especially young people, choose MDMA as their drug of choice due to its stimulating effects. The increased energy for doing their basic life activities makes MDMA as a drug of choice. However, these effects are satisfactorily detrimental to our body systems, particularly neuronal cells. Therefore, it requires more advanced studies on the effects of MDMA on brain damage and behavior as well as the treatments for MDMA disorders.

\section{Ethical Considerations}

\section{Compliance with ethical guidelines}

All ethical principles were considered in this article.

\section{Funding}

The publication of this article is supported by the Ministry of Higher Education, Malaysia (Grant No.: UniSZA/NRGS/2013 (RR057-1)).

\section{Authors' contributions}

All authors contributed equally in preparing all parts of the research.

\section{Conflict of interest}

The authors declared no conflict of interest.

\section{References}

Anneken, J. H., Cunningham, J. I., Collins, S. A., Yamamoto, B. K., \& Gudelsky, G. A. (2013). MDMA increases glutamate release and reduces parvalbumin-positive GABAergic cells in the dorsal hippocampus of the rat: Role of cyclooxygenase. Journal of NeuroImmune Pharmacology, 8(1), 58-65. [DOI:10.1007/s11481-012-9420-x] [PMID] [PMCID]

Asl, S. S., Pourheydar, B., Dabaghian, F., Nezhadi, A., Roointan, A., \& Mehdizadeh, M. (2013). Ecstasy-induced caspase expression alters following ginger treatment. Basic and Clinical Neuroscience, 4(4), 329-33. http://bcn.iums.ac.ir/ article-1-437-en.html

Baumann, M. H., Wang, X., \& Rothman, R. B. (2007). 3, 4-Methylenedioxymethamphetamine (MDMA) neurotoxicity in rats: A reappraisal of past and present findings. Psychopharmacology, 189(4), 407-24. [DOI:10.1007/s00213-006-0322-6] [PMID] [PMCID]

Bradbury, S. (2014). The Role of Serotonin in MDMA Self-administration in rats. Wellington: Victoria University of Wellington. http://hdl.handle.net/10063/3672

Breivik, T., Bogen, I. L., Haug, K. H., Fonnum, F., Opstad, P. K., \& Eide, D. M., et al. (2014). Effects of long-term exposure of 3, 4-methylenedioxymethamphetamine (MDMA;"ecstasy") on neuronal transmitter transport, brain immuno-regulatory systems and progression of experimental periodontitis in rats. Neurochemistry International, 72, 30-6. [DOI:10.1016/j. neuint.2014.04.002] [PMID]

Buchert, R., Thomasius, R., Nebeling, B., Petersen, K., Obrocki, J., \& Jenicke, L., et al. (2003). Long-term effects of "ecstasy" use on serotonin transporters of the brain investigated by PET. Journal of Nuclear Medicine, 44(3), 375-84. http://jnm. snmjournals.org/content/44/3/375.short

Budzynska, B., Michalak, A., Frankowska, M., Kaszubska, K., \& Biała, G. (2017). Acute behavioral effects of co-administration of mephedrone and MDMA in mice. Pharmacological Reports, 69(2), 199-205. [DOI:10.1016/j.pharep.2016.10.006] [PMID]

Cadoni, C., Pisanu, A., Simola, N., Frau, L., Porceddu, P. F., \&Corongiu, S. (2017). Widespread reduction of dopamine cell bodies and terminals in adult rats exposed to a low dose regimen of MDMA during adolescence. Neuropharmacology, 123, 385-94. [DOI:10.1016/j.neuropharm.2017.06.008] [PMID]

Collins, S. A., Gudelsky, G. A., \& Yamamoto, B. K. (2015). MDMA-induced loss of parvalbumin interneurons within the dentate gyrus is mediated by $5 \mathrm{HT} 2 \mathrm{~A}$ and NMDA receptors. 
European Journal of Pharmacology, 761, 95-100. [DOI:10.1016/j. ejphar.2015.04.035] [PMID] [PMCID]

Costa, G., Morelli, M., \& Simola, N. (2017). Progression and persistence of neurotoxicity induced by MDMA in dopaminergic regions of the mouse brain and association with noradrenergic, GAB aergic, and serotonergic damage. $\mathrm{Neu}$ rotoxicity Research, 32(4), 563-74. [DOI:10.1007/s12640-0179761-6] [PMID]

Costa, G., Morelli, M., \& Simola, N. (2018). Repeated Administration of 3, 4-Methylenedioxymethamphetamine (MDMA) elevates the levels of neuronal nitric oxide synthase in the nigrostriatal system: Possible relevance to neurotoxicity. Neurotoxicity Research, 34(4), 763-8. [DOI:10.1007/s12640018-9892-4] [PMID]

Degenhardt, L., Bruno, R., \& Topp, L. (2010). Is ecstasy a drug of dependence? Drug \& Alcohol Dependence, 107(1), 1-10. [DOI:10.1016/j.drugalcdep.2009.09.009] [PMID]

Finnegan, K.T., Skratt, J.J., Irwin, I., Langston, J.W. (1989). The N-Methyl-D-Aspartate (NMDA) receptor antagonist dextrorphan, prevents the neurotoxic effects of 3, 4-methylenedioxymethamphetamine (MDMA) in rats. Neuroscience Letters, 105(3), 300-6. [DOI:10.1016/0304-3940(89)90637-X]

García-Cabrerizo, R., \& García-Fuster, M. J. (2015). Chronic MDMA induces neurochemical changes in the hippocampus of adolescent and young adult rats: Down-regulation of apoptotic markers. Neurotoxicology, 49, 104-113. [DOI:10.1016/j.neuro.2015.06.001] [PMID]

García-Pardo, M. P., Escobar-Valero, C., Rodríguez-Arias, M., Miñarro, J., \& Aguilar, M. A. (2015). Involvement of NMDA glutamate receptors in the acquisition and reinstatement of the conditioned place preference induced by MDMA. Behavioural Pharmacology, 26(5), 411-7. [DOI:10.1097/ FBP.0000000000000138] [PMID]

García-Pardo, M. P., Rodríguez-Arias, M., Miñarro, J., \& Aguilar, M. A. (2017). Role of nitric oxide pathway in the conditioned rewarding effects of MDMA in mice. Behavioural Brain Research, 330, 75-7. [DOI:10.1016/j.bbr.2017.05.010] [PMID]

Kalant, H. (2001). The pharmacology and toxicology of "ecstasy"(MDMA) and related drugs. Canadian Medical Association Journal, 165(7), 917-28.

Kish, S. J. (2002). How strong is the evidence that brain serotonin neurons are damaged in human users of ecstasy? Pharmacology Biochemistry and Behavior, 71(4), 845-55. [DOI:10.1016/S0091-3057(01)00708-0]

Karuppagounder, S. S., Bhattacharya, D., Ahuja, M., Suppiramaniam, V., DeRuiter, J., Clark, R., \& Dhanasekaran, M. (2014). Elucidating the neurotoxic effects of MDMA and its analogs. Life Sciences, 101(1-2), 37-42. [DOI:10.1016/j. lfs.2014.02.010] [PMID]

Laurent, S., \& Safar, M. (1992). Rilmenidine: a novel approach to first-line treatment of hypertension. American Journal of Hypertension, 5(4_Pt_2), 99S-105S. [DOI:10.1093/ ajh/5.4.99S] [PMID]

Li, I. H., Ma, K. H., Weng, S. J., Huang, S. S., Liang, C. M., \& Huang, Y. S. (2014). Autophagy activation is involved in 3, 4-methylenedioxymethamphetamine ('ecstasy')-induced neurotoxicity in cultured cortical neurons. PLoS One, 9(12), e116565. [DOI:10.1371/journal.pone.0116565] [PMID] [PMCID]

Liechti, M. E., Saur, M. R., Gamma, A., Hell, D., \& Vollenweider, F. X. (2000). Psychological and physiological effects of MDMA ("Ecstasy") after pretreatment with the 5-HT2 antagonist ketanserin in healthy humans. Neuropsychopharmacology, 23(4), 396-404. [DOI:10.1016/S0893-133X(00)00126-3]

Lizarraga, L. E., Phan, A. V., Cholanians, A. B., Herndon, J. M., Lau, S. S., \& Monks, T. J. (2014). Serotonin reuptake transporter deficiency modulates the acute thermoregulatory and locomotor activity response to 3, 4-( \pm -methylenedioxymethamphetamine, and attenuates depletions in serotonin levels in SERT-KO rats. Toxicological Sciences, 139(2), 421-31. [DOI:10.1093/toxsci/kfu039] [PMID] [PMCID]

Ma, K. H., Liu, T. T., Weng, S. J., Chen, C. F. F., Huang, Y. S., \& Chueh, S. H. (2016). Effects of dextromethorphan on MDMAinduced serotonergic aberration in the brains of non-human primates using [123 I]-ADAM/SPECT. Scientific Reports, 6(1), 1-8. [DOI:10.1038/srep38695] [PMID] [PMCID]

Mercer, L. D., Higgins, G. C., Lau, C. L., Lawrence, A. J., \& Beart, P. M. (2017). MDMA-induced neurotoxicity of serotonin neurons involves autophagy and rilmenidine is protective against its pathobiology. Neurochemistry International, 105, 80-90. [DOI:10.1016/j.neuint.2017.01.010] [PMID]

Moyano, S., Frechilla, D., \& Del Rio, J. (2004). NMDA receptor subunit and CaMKII changes in rat hippocampus induced by acute MDMA treatment: a mechanism for learning impairment. Psychopharmacology, 173(3-4), 337-45. [DOI:10.1007/s00213-004-1816-8] [PMID]

Mueller, M. A., Yuan, J., Neudorffer, A., Peters, F., Maurer, H., \& Ricaurte, G. A. et al. (2009). Further studies on the role of metabolites in MDMA-induced serotonergic neurotoxicity. Drug Metabolism and Disposition, 37(10), 2079-86. [DOI:10.1124/dmd.109.028340] [PMID] [PMCID]

Mustafa, N. S., Bakar, N. H. A., Adnan, L. H. M., Fauzi, N. F. A. M., Thoarlim, A., \& Mohamad, N., et al. (2018). Protective effects of thymoquinone on the MDMA-induced cerebrospinal fluid serotonin depletion in rats. Transylvanian Review, 1(1). http://www.transylvanianreviewjournal.org/index.php/TR/article/view/2897

Parrott, A. C., Montgomery, C., Wetherell, M. A., Downey, L. A., Stough, C., \& Scholey, A. B. (2014). MDMA, cortisol, and heightened stress in recreational ecstasy users. Behavioural Pharmacology, 25(5 and 6), 458-72. [DOI:10.1097/ FBP.0000000000000060] [PMID]

Popova, D., Forsblad, A., Hashemian, S., \& Jacobsson, S. O. (2016). Non-Serotonergic Neurotoxicity by MDMA (Ecstasy) in Neurons Derived from Mouse P19 Embryonal Carcinoma Cells. PloS One, 11(11), e0166750. [DOI:10.1371/journal.pone.0166750] [PMID] [PMCID]

Potter, A., Downey, L., \& Stough, C. (2013). Cognitive function in ecstasy naive abstinent drug dependants and MDMA users. Current Drug Abuse Reviews, 6(1), 71-6. [DOI:10.2174/18 74473711306010008] [PMID]

Simantov, R., \& Peng, W. (2004). MDMA (Ecstasy) controls in concert a group of genes involved in GABA neurotransmission. FEBS Letters, 563(1-3), 3-6. [DOI:10.1016/S00145793(04)00256-X] 
Tao, R., Shokry, I. M., Callanan, J. J., Adams, H. D., \& Ma, Z. (2015). Mechanisms and environmental factors that underlying the intensification of 3, 4-methylenedioxymethamphetamine (MDMA, Ecstasy)-induced serotonin syndrome in rats. Psychopharmacology, 232(7), 1245-60. [DOI:10.1007/ s00213-014-3759-z] [PMID] [PMCID]

UNODC. Report world 4. 2017. https://www.unodc.org/ wdr2017/index.html

Verrico, C. D., Miller, G. M., \& Madras, B. K. (2007). MDMA (Ecstasy) and human dopamine, norepinephrine, and serotonin transporters: Implications for MDMA-induced neurotoxicity and treatment. Psychopharmacology, 189(4), 489-503. [DOI:10.1007/s00213-005-0174-5] [PMID]

Wunderli, M. D., Vonmoos, M., Fürst, M., Schädelin, K., Kraemer, T., \& Baumgartner, M. R. (2017). Discrete memory impairments in largely pure chronic users of MDMA. European Neuropsychopharmacology, 27(10), 987-99. [DOI:10.1016/j. euroneuro.2017.08.425] [PMID] 
This Page Intentionally Left Blank 